\title{
The Importance of the Teacher for Developing Interest in Learning English by Chinese Students
}

\author{
Yunbao Yang \\ School of Educational Studies (Bundoora Campus), La Trobe University \\ Post code 3083, Melbourne, Australia \\ Tel: $61419396821 \quad$ E-mail: yangyunbaogeorge@hotmail.com
}

\begin{abstract}
The importance of the English teacher for the development of interest by students in the learning of English is discussed. In the Chinese context, the teacher is regarded traditionally as knowledgeable and the source of learning by students. Commonly, learners have no idea why English language is important to them and their interest in English relies on their teacher. A few perspectives are discussed regarding teachers as motivators of the successful learning of English.
\end{abstract}

Keywords: Interest in learning English, Importance of teacher

\section{Introduction}

Gardner and Lambert $(1959,1972)$ and Gardner $(1985,2001)$ have provided extensive descriptions of the factors in social psychology influencing language learning success in a Canadian context. Factors such as interest in language learning, integrative orientation, parental' influences and the attitudes learners hold toward target cultures were raised. These factors affect the success of learning a language and positive attitudes or emotional feelings enhance learning process. Consequently, learners possessing these characteristics are likely to be more successful learners of language than those who do not have the characteristics.

Theoretically, the factors listed above serve as guidelines for language learning and undoubtedly, they set a background scene for second language learning in Canada where language learners have ready access to native language speakers, either English or French. In other words, the language environment is already provided and learners are expected to integrate with the culture in order to be a part of the main stream society and often interest in the language is expected to be present. However, this may not be the case once the language learning context shifts from a second language learning setting to a foreign language one, such as occurs in China where 'interest' in learning can be one of the problems confronting learners.

According to the social psychological theory of Gardner (1985) and Gardner and Lambert (1972), learners are socially and psychologically influenced such that they are interested in learning a foreign language. A key element of this theory is that learners hold an 'interest' either socially or psychologically. Zhao (2002, p.1) noted that "the New Curriculum for Chinese primary schools emphasizes students' empathy to develop their interest in English and help them build up confidence," suggesting the significant role of 'interest' in the learning of English. It seems this emphasis is the result of 'lack of interest' in the majority of Chinese learners of English and the 'high investment but low efficiency' which has been observed over the past two decades.

The question arises as to how language learners become interested in learning in a context which is far from native community where learners are generally out of contact the native English speakers. It seems that the language teacher is critical because s/he teaches the language and often is the first person, and commonly the only person, to introduce the language to the students and the only person who uses the language whom students can contact. Further questions arise too. For example, are students interested in English once they are taught? Why are they interested in learning it? Are they really interested if they achieve well in the course? Why do the majority Chinese English learners fail the course sooner or later? Numerous questions could be asked, but a key issue is the correlation between the teacher and interest in English on the part of students.

\section{The understanding of 'interest in' English}

Krapp et al. (1992) proposed that there are three definitions of interest. The three definition cover personal interest, situational interest, and interest as a psychological state. (Elliott, 2005, p. 28) noted that "personal interest is seen as a relatively stable and enduring characteristic of an individual. Situational interest is more transitory and is elicited by 
conditions in the environment that focus attention and generated affect." In considering the situation in China, Hau et al. (1996) considered:

Chinese parents strongly emphasize to their children that if one works hard, one will slowly build up one's interest and study skills. The learning of study skills and the cultivation of interest will subsequently lead to an improvement in ability. In contrast, the Western philosophy which stresses individualism and states that interest should come naturally. (p.135)

These authors further noted that Chinese "students are encouraged to learn by drill because it is believed that their interest in study, which initially may be totally lacking, will be cultivated later through their repetitive work" (Hau et al. 1996, p.134-135). It appears that in the Chinese context there is a possible lack of interest in English for one reason or another and learners try to obtain competency with English by conducting drills in which interest is supposed to appear in their learning. Seemingly, Chinese learners do not possess much interest in English, given their learning styles or strategies.

In connection with the latter, very recently, Jiang (2004) surveyed 106 students in year 9 of schooling in Zhejiang Province of the People's Republic of China regarding their motivation. It was found that only $12 \%$ students were interested in learning English.

Pintrich (1996) previously noted that "in school there are many students who have low intrinsic motivation and an important goal for teachers is to raise motivation" (p. 277). To enhance intrinsic motivation, attention must be given to the four areas: challenge, curiosity, control, and fantasy (Lepper \& Hodell, 1989). Consequently, a teacher's role in the development of interest on the part of students appears to be even more important due to the authoritative position of the teacher in the Chinese culture.

\section{The role of the teacher}

Teachers play a key role in the academic achievements of their students and in the Chinese context, learners depend heavily on their teachers, especially for English courses. Meece (1991) claimed that teachers who motivate students to learn often develop intrinsic motivation in students to learn for the sake of knowledge. In the Chinese classroom setting, a teacher of English is the authority of English knowledge and is regarded as the knower of the target culture and students are there to be introduced to learn a totally new foreign language. It is understood that English is not a part of the Chinese culture and naturally, students often find it hard to have an interest in the course. Consequently, they depend on their teacher to develop interest so that they might learn English This is important to them because the test score in English often determines whether a student can stand a place in class or has the possibility to go to a higher level junior secondary school, senior secondary school or even for university education. It is known that English is a major course in the school curriculum in China and developing interest in the course is a significant step for realization of the above aforesaid purposes. However, without a teacher's assistance and guidance, students will find it impossible to proceed. Significantly, Pintrinck and Schunk (1996) claimed that “enthusiastic teachers help foster students' interest and motivation in learning" (p.171).

An important process influencing student motivation involves the expectations that teachers hold for student learning and performance. Researchers on teacher expectations in the past 25 years have addressed such issues as how teachers form expectations, how they communicate them to students, and how these expectations affect outcomes (Braun, 1976; Cooper \& Good, 1983; Cooper \& Tom, 1984; Dusek, 1985; Jussim, 1986, 1991). Schumann (2000) proposed a different view on the issue of "motivation of learners' by querying "how can teachers get students interested in acquiring a second language?' (p.4). This researcher obviously highlighted the importance of a teacher for developing interest in language learning. However, the expectations of a teacher for the academic performance of the student should be based on the establishment of a rapport which facilitates beneticial outcomes.

\section{Teacher-student rapport}

Learning success relies on both teacher and student, not on the materials, so a relationship is important. Schon (1987, p.3) stated that "researchers are now realizing that education does not take place in a laboratory but in a 'soft, slimy swamp." This indicates the complexity of the learning process which involves teacher-student rapport and many other factors. Zhao (2002, p.3) also noted that "a teacher needs to be tolerant in order to create a relaxing psychological atmosphere to share students' worries and concerns." Only under this condition can students approach the teacher for help and assistance to solve their own problems in learning and it is reasonable to assume the language teacher is probably the only option available for them.

In terms of teacher-student relations, a feeling of concern, care, support, and respect for students and positive teacher-student interactions will be associated with positive motivational outcomes (Natriello, 1986; Midgley, Feldaufer, \& Eccles, 1989; also see Calabrese \& Poe, 1990; Eccles, Midgley, et al., 1993). In this connection, Bryke, Lee, and Holland (1993) in their study of Catholic schools observed that a concern for the welfare of others or the creation of a 
caring community can have very positive effects for all students, even those from populations that would be at risk of school failure.

Teacher-student rapport is a highlighted area in the Chinese educational system. This is because "the teacher-student relationship plays an important role in determining the atmosphere of the teaching environment and this combination influences the quality of learning that takes place" (Chambers, 1999, p.35). Thus the teacher-student relationship plays an extremely important part in the success or failure of teaching and learning ( $\mathrm{Li}, 1999)$. The relationship is important for development of interest in and the learning; 'liang shi yiyou' (good teacher and helpful friend) is consistent with establishment of interest in the course on the part of students with the help of their teachers.

Gardner (1985) also considered the importance of the' attitudes of students toward the course and their language teachers. He noted that because the language teacher would be regarded as the focus of the language, it is reasonable to assume that the teacher was the only language user they knew and the only place they possibly use the language would be the classroom. Consequently, the course and the teacher can become closely associated with the language material, and attitudes toward them could thus become highly influential. In contrast, in other subject areas, the material has some link with the individual's own culture; hence, the course and the teacher are not the only focuses (Gardner, 1985, p.7).

Zhang et al. (2003) conducted research in the Number Eight Secondary School in Beijing (a National Key School) by asking students to evaluate their relationships with their teachers. Zhang and her colleagues found that the students' main environment was the school and they tried to adjust themselves to be accepted, to be liked or to be appreciated by their teachers. When the students were in an ideal student-teacher relationship, they would feel capable and healthy in mind; they were confident and had high self-esteem. Consequently, they adopted a positive attitude.

These observations led Yang (2004) to suggest that the students who were in a safe student-teacher relationship, concentrated well and more often with a down-to-earth attitude to learning so as to enhance their learning efficiency. In contrast, a bad teacher-student relationship would always threaten the students and they constantly feared seeing the teacher. Both Zhang et al. (2003) and Yang (2004) agreed that student-teacher rapport played an essential part for the learning success of students. They considered this rapport made teachers approachable and therefore provided students with chances to talk to their teachers and consequently facilitated learning outcomes.

Teacher-student rapport is critical not because it is the development of a personal relationship, but it emphasizes more the role for teachers in understanding students through the teaching process and in return helps students to develop interest in learning. Teacher-student rapport becomes a measure to understand academic performance of students in the Chinese setting. It appears that those who have a close contact with their English teachers often are interested in learning English.

In the development of teacher-student rapport, various learning experiences occur and these positive/negative experiences have strong impacts on students who develop their interest and confidence because they are appreciated by the language teacher rather than feeling frustrated and discouraged due to failure and humiliation as language learning is a 'soft and slippery area.'

\section{Positive and negative learning experiences}

Zhang and Ding (1996) noted that a desirable disposition of a teacher always attracts students; students often transfer their 'respect' of the teacher to 'fond of' the course s/he teaches and finally convert this into motivation in learning. Wang (1996, p.32) also claimed that "a good teacher understands the classroom learning environment and understands better the unexpected result by giving a praise look, a smile, a nod and a word of encouragement." More recently, Yang (2004) considered that the generosity of a teacher in giving positive feedback and creating a positive learning environment promotes student learning. In spite of this, it should be noted that "a teacher who overcorrects the student can lower the expectation for success and destroy the possibility of a reward, thus reducing the students' willingness to pay attention or to persist in language learning (Okada et al., 1996, p.105).

Among different elements of motivation, the experience of the learner is one of the prominent characteristics that affects the interest in learning. Researchers including Rubin and Ryan (1982) and Deci and Ryan (1992) have proved that successful language learners have positive learning experiences while those who fail in learning usually relate to negative experiences. Past success in a particular situation would make a person more likely to engage in achievement behaviours in a similar situation in the future; past failure would generate fear and stifle achievement (Oxford \& Shearin, 1996, p.125). Nakata (2006) considered that learning success and positive learning experience are correlated.

Positive and negative learning experiences are related directly to language learning success because a positive learning experience encourages learners and negative experience proves the defeat in learning. However, positive and negative learning experiences often occur in classroom or classroom-related activities and very often it is a matter of teacher-involvement. In this connection, Rivers (1964, p.92) noted that "foreign language learning classrooms are a fertile ground for frustration, anxiety, embarrassment and humiliation" and Rubin and Thompson (1982, p. 10) considered that "previous experiences with foreign language study may influence attempts" 
The quality of the experience, as well as the achievement itself, are extremely important (Deci \& Ryan, 1992, p.31). With regard to the quality of the experience in learning English as a foreign language, it would be luxurious to expect learners to have quality experience by contacting English native speakers. This is because the setting pre-determines the context where learners are unlikely to have a quality experience. For example, in China it is likely that the majority of learners of English will encounter some negative feedback during the learning process. Quality experience can hardly be guaranteed if an English teacher is neither student-loving nor enthusiastic in teaching.

Negative experience often is associated with physical or language misuse in learning activities, especially in classrooms and in public. For example, Ho (1981, p.89) stated that "physical punishment in school, such as hitting the pupils' hand, is still practised. Ridicule or shaming of the children, such as making them stand out before their classmates, remains a common technique of control." Wong (1992), in a survey of secondary school teachers in Hong Kong, reported that the banning of corporal punishment remained an isolated attempt to improve the pastoral system

More recently, Zhu (2001, p.161) commented that "student's like or dislike of a course is connected with their early learning experiences." Those who experienced failure in learning were likely to be rebuked and their learning incentives withered, leaving no more interest in the course. In contrast, those who liked the course showed strong interest in it. These observations are consistent with the notion that the teacher's personality was closely related to learning success of students. A similar conclusion was reached by Yang (2004) who also considered that it was difficult for students to experience success when the teacher's personality was harsh and cold. This conclusion was reinforced by the observation of Zhou and He (2005) who investigated the learning of English in almost 100 secondary schools in China. They found that 'teacher-student rapport' was one of the most important factors which affected the learning of English in the eyes of students.

The dominant role English plays should not be overlooked in a context where English is treated as a foreign language in China. Students face materials from another cultural community, but more importantly, they are not required to learn the language simply to acquire another language. Instead, they need to learn it as a part of their life, even though the language seems remote and distant from their daily life. This further highlights the importance of the language teacher as a source of motivation for developing the ability of students to learn English.

\section{Conclusion}

In the Chinese context the teacher of English has a unique role and the special position is even more important than teachers of other disciplines. Furthermore, the English teacher is not only a facilitator as in western cultures. Teacher-student rapport and students' learning experience are critical for raising the 'interest in English learning' in students.

\section{References}

Braun, C. (1976). Teacher expectation: Sociopsychological dynamics. Review of Educational Research, 46, 185-213.

Bryk, A., Lee, V. \& Holland, P. (1993). Catholic schools and the common good. Cambridge, MA: Harvard University Press.

Calabrese, R., \& Poe, J. (1990). Alienation: An explanation of high school dropout rates among African-American and Latino students. Educational Research Quarterly, 14, 22-26.

Chambers, G. N. (1999). Motivating language learners. Sydney: Multilingual Matters Ltd.

Chen, C. S., Lee, S. Y. \& Stevenson, H. W. (1996). Academic achievement and motivation of Chinese students. In S. Lau, (Ed.), Growing up the Chinese way: Chinese child and adolescent development (pp: 69-91). Hong Kong: The Chinese University Press.

Cooper, H. M. \& Good, T. L. (1983). Pygmalion grows up: Studies in the expectation communication process. New York: Longman.

Cooper, H. M. \& Tom, D. Y. H. (1984). Teacher expectation research: A review with implications for classroom instruction. Elementary School Journal, 85, 77-89.

Deci, E. L. \& Ryan, R. M. (1992). The initiation and regulation of intrinsically motivated learning and achievement. In A. K. Boggiano \& T. S. Pittman (Eds.), Achievement and motivation: A social-developmental perspective (pp.9-36). Cambridge: Cambridge University.

Dornyei, Z. (2001). Motivational strategies in the language classroom. Cambridge: Cambridge University Press.

Dusek, J. B. (1985). Teacher expectancies. Hillsdale, NJ: Erlbaum.

Eccles, J., Midgley, C., A., Buchnnan, C., Reuman, D., Flaanagan, C. \& Mac Iver, D. (1993). Development during adolescence: The impact of stage-environment fit on young adolescents' in schools and families. American Psychologist, $48,90-101$. 
Elliott, J. G., Hufton, N. R., Willis, W. \& Illushiin, L. (2005). Motivation, engagement and educational performance: International perspectives on the contexts for learning. New York: Palgrave Macmillan.

Gardner, R. C. \& Lambert, W. E. (1959). Motivational variables in second language acquisition. Canadian Journal of Psychology, 13, 266-272.

Gardner, R. C. \& Lambert, W. E. (1972). Attitudes and motivation in second - language learning. Rowley, Massachusetts: Newbury House Publishers.

Gardner, R. C. (1985). Social psychology and language learning: The role of attitudes and motivation. London, Ontario: Edward Arnold.

Gardner, R. C. (2001). Integrative motivation and second language acquisition. In Z. Dornyei \& R. Schmidt (Eds.), Motivation and second language acquisition (pp. 1-20). Hawaii: University of Hawaii.

Hau, K. T. \& Salili, F. (1996). Achievement goals and causal attributions of Chinese students. In Lau, S. (Ed.), Growing up the Chinese way: Chinese child and adolescent development (pp:121-145). Hong Kong: The Chinese University Press.

Ho, D. Y. F. (1981). Traditional pattern of socialization in Chinese society. Acta Psychologica Taiwanica, 23, 81-95.

Jiang, X. N. (2004). Emphasizing on the selection of reading material to improve students reading ability. English Teaching and Research Notes, 4, 31-33.

Jussim, L. (1986). Self-fulfilling prophecies: A theoretical and integrative review. Psychological Review, 93, 429-445.

Jussim, L. (1991). Social perception and social reality: A reflection-construction model. Psychological Review, 98, 54-73.

Krapp, A., Hidi, S. \& Renninger, K. A. (1992). Interest, learning, and development. In K. A. Renninger, S. Hidi \& A. Krapp (Eds.), The role of interest in learning and development (pp.3-25). Hillsdale, NJ: Erlbaum.

Lepper, M. r. \& Hodell, M. (1989). Intrinsic motivation in the classroom. In C. Ames \& R. Ames (Eds.), Research on motivation in education (Vol. 3, pp. 73-105). San Diego: Academic Press.

Meece, J. (1991). The classroom context and students' motivational goals. In M. L. Maehr \& P. R. Pintrich (Eds.), Advances in motivation and achievement (Vol. 7, pp.261-286). Greenwich, CT: JAI Press.

Midgley, C., Feldlauger, H. \& Eccles, J. (1989). Change in teacher efficacy and student self-and task-related beliefs in mathematics during the transition to junior high school. Journal of Educational Psychology, 81, 247-258.

Nakata, Y. (2006). Motivation and experience in foreign language learning. Bern: International Academic Publishers.

Natriello, G. (1986). School dropouts: patterns and policies. New York: Teachers' College Press.

Okada, M., Oxford, R. \& Abo, S. (1996). Not all alike: Motivation and learning strategies among students of Japanese and Spanish in an exploratory study. In R. Oxford (Ed.), Language learning motivation: pathways to the new century (pp.105-120). Hawaii: University of Hawaii

Oxford, R. L. \& Shearin, J. (1996). Language learning motivation in a new key. In R. Oxford (Ed.), Language learning motivation: pathway to the new century (pp.121-144). Honululu: Second Language Teaching and Curriculum Centre: University of Hawaii at Manoa.

Pintrich, P. R. \& Schunk, D. H. (1996). Motivation in Education. NJ: Prentice-Hall, Inc. A Simon \& Schuster Company, Englewood Cliffs.

Rivers, W. M. (1964). The psychologist and the foreign language teacher. Chicago: Chicago Press.

Schumann, J. H. (2000). Getting the student's attention: insight from evolution. Applied Linguistics Forum (official newsletter of the TESOL, applied linguistics interest section), 20, 4-5.

Schunk, D. H. (1989). Self-efficacy and cognitive skill learning volume 3 goals and cognitions. In C. Ames \& R. Ames (Eds.), Research on motivation in education (pp: 13-44). New York: Harcourt Brace Jouvanovich, Publishers.

Wang, T. (1996). Developing interest in English course in primary pupils. English Teaching and Research Notes, 5, 30-32.

Wong, O. H. F. (1992). Perceived effectiveness of rewards and punishment by secondary school students. Unpublished Master's dissertation, Psychology Department, The University of Hong Kong.

Yang, Y. B. (2004). Characteristics of good English learners - urban key senior secondary school students learning English in Yunnan - China. Unpublished MA thesis. Melbourne: La Trobe University.

Zhang, F. L., Shi, X. Y. \& Tan, Y. (2003). Teacher-student relationship affects learning results. (Research report) at the $4^{\text {th }}$ academic conference of Chinese psychology association. Beijing. 
Zhang, Y. G. \& Ding, F. (1996). The essential dispositions of a language teacher. Foreign Language World, 3 , 57-64.

Zhao, X. J. (2002). Current teachers' roles in "English curriculum standard." English Teaching and Research Notes, 11, $1-3$.

Zhou, R. \& He, G. Z. (2005). Investigation on empathy in English teachers of secondary school. Foreign Language Teaching in Schools, 2, 1-5. 